\title{
Glucose-6-Phosphatase Mutation G188R Confers an Atypical Glycogen Storage Disease Type 1b Phenotype
}

\author{
BRENT W. WESTON, JU-LI LIN, JOSEPH MUENZER, H. SCOTT CAMERON, \\ ROLAND R. ARNOLD, HANS H. SEYDEWITZ, ERTAN MAYATEPEK, EMILE VAN \\ SCHAFTINGEN, MARIA VEIGA-DA-CUNHA, DIETRICH MATERN, AND Y.T. CHEN \\ Department of Pediatrics [B.W.W., J.M., H.S.C.], and the Dental Research Center [R.R.A.], University of \\ North Carolina at Chapel Hill, North Carolina 27599-7220, U.S.A.; University Children's Hospital \\ [H.H.S.], Albert-Ludwigs-University, Freiburg, Germany; Department of General Pediatrics [E.M.], \\ Ruprecht-Karls-University, Heidelberg, Germany; Laboratory of Physiological Chemistry [E.V.S., \\ M.V.D.C.], Universite Catholique de Louvain, Brussels, Belgium; and Department of Pediatrics [D.M., \\ Y.T.C.], Duke University Medical Center, Durham, North Carolina 27710, U.S.A.
}

\section{ABSTRACT}

\begin{abstract}
Glycogen storage disease type 1a (GSD 1a) is caused by a deficiency in microsomal glucose-6-phosphatase (G6Pase). A variant (GSD 1b) is caused by a defect in the transport of glucose-6-phosphate (G6P) into the microsome and is associated with chronic neutropenia and neutrophil dysfunction. Mutually exclusive mutations in the G6Pase gene and the G6P transport gene establish GSD 1a and GSD $1 \mathrm{~b}$ as independent molecular processes and are consistent with a multicomponent translocase catalytic model. A modified translocase/catalytic unit model based on biochemical data in a G6Pase knockout mouse has also been proposed for G6Pase catalysis. This model suggests coupling of G6Pase activity and G6P transport. A 5-mo-old girl with hypoglycemia, hepatomegaly, and lactic acidemia was diagnosed with GSD 1a. She also developed neutropenia, neutrophil dysfunction, and recurrent infections characteristic of GSD 1b. Homozygous G188R mutations of the G6Pase gene were identified, but no mutations in the G6P translocase gene were found.
\end{abstract}

We have subsequently identified a sibling and two unrelated patients with similar genotypic/phenotypic characteristics. The unusual association of neutrophil abnormalities in patients with homozygous G188R mutations in the G6Pase gene supports a modified translocase/catalytic unit model. (Pediatr Res 48: 329334, 2000)
GSD, glycogen storage disease
G6Pase, glucose-6-phosphatase
G6P, glucose-6-phosphate
PMN, polymorphonuclear neutrophils
PMA, phorbol-myristate-acetate
fMLP, $N$-formyl-met-leu-phe
SSCP, single-strand conformation polymorphism
G-CSF, granulocyte-colony stimulating factor

GSD type 1 is an autosomal recessive disorder that presents with severe hypoglycemia, hepatomegaly, lactic acidemia, hyperlipidemia, and hyperuricemia. Two major subgroups of this inborn error of metabolism have been defined based on clinical and biochemical criteria. GSD type 1a (GSD 1a) is caused by a deficiency in microsomal G6Pase (E.C. 3.1.3.9). G6Pase catalyzes the terminal reaction in gluconeogenesis and glycogenolysis (hydrolysis of G6P) within the endoplasmic reticulum (ER) of hepatocytes and renal epithelial cells (1-4). A

Received December 8, 1999; accepted April 3, 2000.

Correspondence and reprint requests: Brent W. Weston, M.D., Department of Pediatrics, CB 7220, Division of Hematology/Oncology, University of North Carolina at Chapel Hill, NC 27599-7220, U.S.A.

Supported in part by a grant from the National Institutes of Health, NIDDK \#39078 (to Y.T.C.). variant subgroup, GSD $1 \mathrm{~b}$, is caused by a defect in the transport of the substrate G6P into the microsome. GSD $1 \mathrm{~b}$ is associated with normal G6Pase catalytic activity in disrupted microsomes, chronic neutropenia, and neutrophil dysfunction $(5,6)$ in addition to the aforementioned clinical manifestations of GSD 1a.

Mutations in the G6Pase gene (7-10) and the G6P translocase gene (11-14) have established GSD 1a and GSD 1b as independent molecular defects and provide support for the multicomponent translocase catalytic model. This biochemical model proposes that G6Pase function involves the action of three integral proteins: the G6P-specific translocase (T1 transporter) that controls entry of G6P into the ER; a second translocase, denoted T2, that mediates efflux of phosphate; and the phosphohydrolase itself with its lumenal catalytic domain. 
Since the cloning of $\mathrm{T} 1$ and definition of mutations at this locus, it appears likely that the $\mathrm{T} 1$ translocase performs both transport functions, the import of G6P into and transport of phosphate out of the microsome (15-19). In either event, mutations in the G6Pase gene have not been associated with abnormalities of PMN.

A modified translocase/catalytic unit model, supported by biochemical data in G6Pase knockout mice, has also been proposed for G6Pase catalysis (20). This kinetic model suggests coupling of transport and catalysis, with G6Pase activity being important for optimal G6P transport. Although this model originally proposed a single membrane-spanning protein, several recent lines of evidence (including isolation of the T1 cDNA) have led to the modified version (19-21). Despite these biochemical findings, changes in G6P transport have not been associated with catalytic defects in patients with GSD 1a. Nor have any GSD 1a patients shown the typical PMN findings of patients with mutations in the T1 translocase gene. Although G6Pase activity is demonstrable in the ER of human PMN (22), the relatively low transcript levels of G6Pase in PMN would seem to preclude a role in normal leukocyte function $(13,14)$.

We report an infant girl, her brother, and two unrelated patients homozygous for the G188R mutation of G6Pase who had recurrent infections, neutropenia, and neutrophil dysfunction typical of GSD 1b due to defects in the T1 transporter.

\section{METHODS}

Clinical description. The index case, a female infant born to nonconsanguineous parents, was referred at age 3 mo for evaluation of dehydration, poor weight gain, hepatomegaly, fasting hypoglycemia, lactic acidemia, recurrent infections, and neutropenia. Initial laboratory studies showed an arterial blood gas of pH 7.22, $\mathrm{PCO}_{2} 16.8 \mathrm{~mm} \mathrm{Hg}(2.2 \mathrm{kPa}), \mathrm{HCO}_{3}{ }^{-} 6.7$ $\mathrm{mM} / \mathrm{L}$, and lactate $11.6 \mathrm{mM} / \mathrm{L}$. The serum triglycerides exceeded $1000 \mathrm{mg} / \mathrm{dL}(11.3 \mathrm{mM} / \mathrm{L})$, and the uric acid was elevated. The initial white blood count was $7.4 \times 10^{3} / \mu \mathrm{L}$ with an absolute neutrophil count (ANC) of 400. A diagnostic fasting challenge with serial glucose and lactate levels revealed glucose $85 \mathrm{mg} / \mathrm{dL}(4.7 \mathrm{mM} / \mathrm{L})$ at $15 \mathrm{~min}, 69 \mathrm{mg} / \mathrm{dL}(3.8$ $\mathrm{mM} / \mathrm{L})$ at $1 \mathrm{~h}$, and $48 \mathrm{mg} / \mathrm{dL}(2.7 \mathrm{mM} / \mathrm{L})$ at $2 \mathrm{~h}$; the lactate was $6.3 \mathrm{mM} / \mathrm{L}$ at $2 \mathrm{~h}$. At $2.5 \mathrm{~h}$, the glucose was $31 \mathrm{mg} / \mathrm{dL}(1.7$ $\mathrm{mM} / \mathrm{L}$ ) and the lactate $7.2 \mathrm{mM} / \mathrm{L}$. The trial was terminated, the mother fed the infant, and glucose levels subsequently increased. Lactate levels continued to increase, peaking at 8.9 $\mathrm{mM} / \mathrm{L} 4 \mathrm{~h}$ after the onset of fasting.

At age 5 mo, a liver biopsy was performed. G6Pase deficiency was demonstrated by enzymatic assays of fresh and frozen tissue. Neutropenia persisted and recurrent infections worsened. A bone marrow aspirate showed slight myeloid hypoplasia (M:E = 1:1) and eosinophilia. Cytogenetic studies were normal. She was started on a 12-mo trial of G-CSF, 2 $\mu \mathrm{g} / \mathrm{kg}$ s.c., three times weekly. The ANC promptly rose to normal on G-CSF, and a repeat bone marrow aspirate was normal. Approximately 3 mo after discontinuing G-CSF, the neutrophil count fell to pretreatment levels (ANC 300-600), myeloid hypoplasia and marrow eosinophilia recurred, and the patient again became infected. Therapy with G-CSF was resumed. There was normalization of peripheral blood and bone marrow findings.

At age 9 mo, bilateral pressure equalization tubes were placed because of recurrent otitis media. At age $14 \mathrm{mo}$, the patient had bilateral ureteroneocystostomy because of recurrent urinary tract infections including pyelonephritis and documented vesicoureteral reflux. G-CSF therapy was resumed at age $21 \mathrm{mo}$; she has remained on this therapy and done well since then. When the patient was 44 mo old, a sibling was born who developed vomiting, hypoglycemia, hepatomegaly, and lactic acidemia. At the age of $6 \mathrm{wk}$, he was found to have otitis media, neutropenia, and neutrophil dysfunction. Two unrelated GSD 1a patients with homozygous G188R mutations were found to have classic GSD 1a enzymology. Investigation of these patients also showed chronic neutropenia and neutrophil dysfunction.

G6Pase enzyme assays. Phosphohydrolase activity was determined on extracts from percutaneous liver biopsy specimens according to previously described methods (18-21). Assays were performed on both intact and disrupted microsomes (2, 3). Reaction mixtures $(100 \mu \mathrm{L})$ contained $50 \mathrm{mM}$ cacodylate, pH 6.5, $10 \mathrm{mM}$ G6P, $2 \mathrm{mM}$ EDTA, and appropriate amounts of cell homogenates. Samples were incubated at $30^{\circ} \mathrm{C}$ for 10 min. Absorbance was determined at $820 \mathrm{~nm}$ and correlated to the amount of phosphate released according to a standard curve determined with inorganic phosphate control solutions (7).

Neutrophil function studies. Peripheral blood samples were obtained with the parents' informed consent. PMN were separated from heparinized peripheral blood (23). Oxidative metabolism studies were performed using a previously described quantitative $2^{\prime}, 7^{\prime}$-dichlorofluorescein diacetate (DCFH/DA) flow cytometric method (24). Results were confirmed by spectrophotometric measurement of superoxide anion production after stimulation of PMN with the agonists PMA and PMLP (25). Chemotaxis of PMN (26) was measured by migration under agarose (soft agar containing $0.8 \%$ agarose and $0.2 \%$ gelatin) in response to varying concentrations of fMLP $\left(10^{-5}\right.$ to $10^{-9} \mathrm{M}$ ). Spontaneous motility was evaluated using medium without fMLP. Specific migration was defined as movement toward the chemotactic peptide minus migration in the opposite direction. Phagocytosis and killing of microbes was quantitated using a previously described dual fluorescence assay (27). Opsonization, staining, and UV microscopy were performed as described (27-29).

G6Pase mutation analyses. Genomic DNA was extracted from peripheral blood leukocytes (30). The entire coding region and exon/intron junctions of the G6Pase gene were amplified using primers and conditions described previously ( 7 , 31). To identify the mutations at the nucleotide level, PCRamplified genomic DNA fragments were subcloned directly into the vector pCR2.1 using a commercial kit (Invitrogen) and sequenced in their entirety. To assess the presence of this mutation in other patients and relatives, SSCP analysis (31) was performed using the Phastsystem (Pharmacia Biotech). Electrophoresis was carried out under previously described conditions (31). 
Transfection of mutant and control alleles. To construct the G188R mutant cDNA, site-directed mutagenesis was performed (3). The construction was confirmed by DNA sequencing. Wild-type G6Pase cDNA or mutant G188R cDNA in a pcDNA3 vector (Invitrogen) was transiently transfected into COS-7 cells by the DEAE-dextran method (30). The vector pcDNA3 without an insert was used as a negative (mock) transfection control. G6Pase activity was measured on extracts prepared from the transfected cells (7).

SSCP and sequencing analyses for the G6P translocase (or $T 1$ transporter) gene. PCR reactions were performed with primers in $10-\mu \mathrm{L}$ volumes containing $10-20 \mathrm{ng}$ of genomic DNA template, 1X PCR buffer (Boehringer), $180 \mu \mathrm{M}$ of each dNTP, $0.2 \mu \mathrm{M}$ of each ${ }^{32} \mathrm{P}$-end-labeled primers (12), and $0.5 \mathrm{U}$ of Taq DNA polymerase (Boehringer). The PCR and electrophoresis conditions were as previously described (12). Direct sequencing of PCR products showing a shift in SSCP analysis was performed on both strands using the dsDNA Cycle Sequencing System (GIBCO-BRL).

\section{RESULTS}

Hepatocytes from the index case are deficient in G6Pase catalytic activity. Phosphohydrolase activity was measured in liver biopsy specimens from the patient and controls. G6Pase activity was absent in both intact and disrupted microsomal preparations (patient, $<0.075 \mathrm{U}$; control, $3.5 \mathrm{U}$; defined as $\mu \mathrm{M} \cdot \mathrm{min}^{-1} \cdot \mathrm{g}^{-1}$ tissue), consistent with the GSD 1a phenotype (2).

Proband and sibling have chronic neutropenia responsive to $\boldsymbol{G}-\boldsymbol{C S F}$. The duration and severity of chronic neutropenia and response to G-CSF seen in the proband is similar to patients with GSD 1b. In particular, the proband had recurrent Escherichia coli infections that resolved with appropriate treatment. Trials off cytokine therapy confirmed the chronic nature of the neutropenia associated with this mutation. Due to recurrent infections, chronic neutropenia, and neutrophil dysfunction, the sibling has recently started cytokine therapy. Neither parent is affected (data not shown). Within the spectrum of severity of chronic neutropenia and bacterial infections reported in GSD 1b (32-36), our patients' clinical findings suggest a relatively mild course.

$P M N$ isolated from the index case and sibling show impaired function similar to GSD 1 b PMN. Oxidative burst studies were performed on patient, sibling, and control PMN by flow cytometry and spectrophotometric assays. Figure 1 and Table 1 show that the proband's PMN form two distinct functional subpopulations, one with normal respiratory burst measurements and the second with reduced superoxide production. Spectrophotometric assays of patient, sibling, and control PMN confirmed these results (Table 2). These findings are strikingly similar to results with GSD 1b PMN (26).

Chemotaxis is consistently abnormal in GSD $1 b(26,32)$. In our experiments, normal PMN showed peak-specific migration at $10^{-7} \mathrm{M}$ of chemoattractant, whereas patient and sibling PMN showed little or no migration at fMLP concentrations of $10^{-5}$ to $10^{-9} \mathrm{M}$. Quantitative phagocytosis and killing assays (27-29) showed consistent reductions in the percentage of

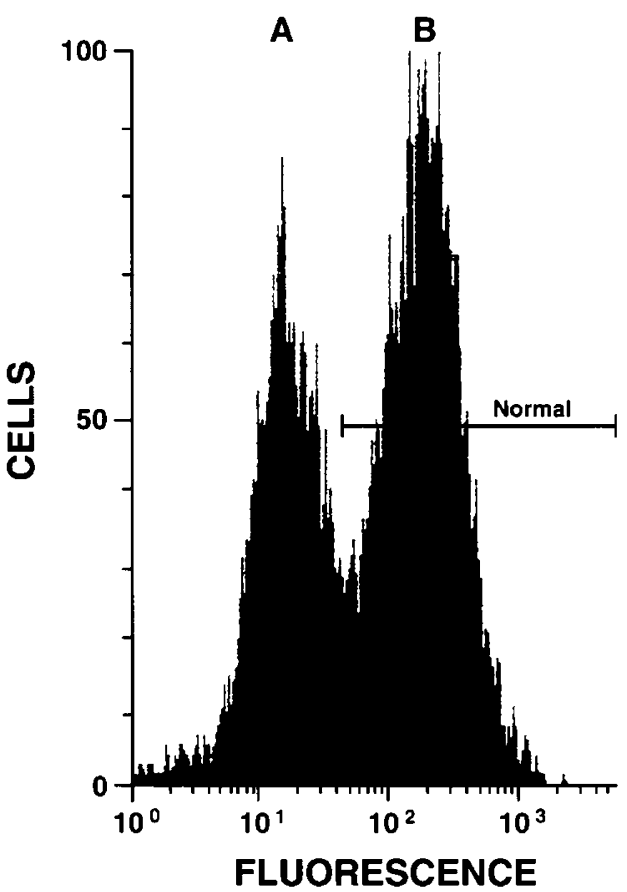

Figure 1. Flow cytometry histogram of patient $\mathrm{PMN}$ in one of three representative $2^{\prime}, 7^{\prime}$-dichlorofluorescein diacetate $(D C F H / D A)$ experiments. After PMA stimulation, the patient's histogram showed two distinct peaks, $(A)$ low oxidative activity and $(B)$ normal activity. Stimulated control $\mathrm{PMN}=$ right cursor, labeled normal. See also Table 1.

Table 1. Oxidative metabolism of patient and control PMN by flow cytometric analysis

\begin{tabular}{ccc}
\hline PMN & Resting & PMA-stimulated \\
\hline Patient & 4.2 & $11.2 / 186^{*}$ \\
Control & 3.7 & 344 \\
\hline
\end{tabular}

* After PMA stimulation, the patient's histogram showed two distinct peaks (see also Fig. 1). Numbers represent mean fluorescence intensity of triplicate samples. Studies were performed using a quantitative DCFH/DA method (Ref. 24).

Table 2. Oxidative metabolism of patient, sibling, and control PMN by spectrophotometric analysis

\begin{tabular}{ccc}
\hline PMN & PMA & fMLP/cytoclasin b \\
\hline Patient & 16.5 & 0.7 \\
Sibling & 20.4 & 2.6 \\
Control & 29.7 & 5.9 \\
\hline
\end{tabular}

Numbers represent $\mathrm{V}_{\max }$ in $\mathrm{mOD} / \mathrm{min} / 5 \times 10^{5} \mathrm{PMN}$, mean value of four measurements; inhibitable with superoxide dismutase. Multiple experiments were performed with proband and control PMN. Data presented are representative from concurrent assays using proband, sibling, and control PMN. Resting PMN data not shown.

patient and sibling PMN to kill E. coli and Porphyromonas gingivalis (Table 3 ). In contrast, there was normal phagocytosis and killing of Staphylococcus aureus (same). These functional defects correlate with the proband's infectious course and with results using GSD $1 b \operatorname{PMN}(26,32)$. Similar results were found in PMN from two unrelated G188R patients (below).

Proband is homozygous for G188R, and two unrelated G188R homozygotes have PMN abnormalities. DNA sequencing analysis of the entire coding region and the exon/ intron junctions of the G6Pase gene showed a $\mathrm{G}$ to $\mathrm{C}$ trans- 
Table 3. Phagocytosis and killing studies with patient, sibling, and control PMN

\begin{tabular}{llrrr}
\hline Organism & & $\begin{array}{c}15 \mathrm{~min} \\
(\%)\end{array}$ & $\begin{array}{c}30 \mathrm{~min} \\
(\%)\end{array}$ & $\begin{array}{c}45 \mathrm{~min} \\
(\%)\end{array}$ \\
\hline S. aureus & $\mathrm{P}$ & 79 & 85 & 90 \\
& $\mathrm{~S}$ & 89 & 93 & 100 \\
\multirow{3}{*}{ E. coli } & $\mathrm{C}$ & 100 & 100 & 100 \\
& $\mathrm{P}$ & 4 & 32 & 50 \\
P. gingivalis & $\mathrm{S}$ & 5 & 28 & 49 \\
& $\mathrm{C}$ & 20 & 55 & 76 \\
& $\mathrm{P}$ & 13 & 45 & 48 \\
& $\mathrm{~S}$ & 21 & 51 & 52 \\
& $\mathrm{C}$ & 32 & 83 & 95 \\
\hline
\end{tabular}

Percentages represent PMN with more than three bacteria ingested per cell and greater than $50 \%$ nonviable intracellular organisms (mean of three experiments). $P=$ proband PMN; $S=$ sibling PMN; $C=$ control PMN.

version at position 641 of the G6Pase cDNA in all five clones sequenced (Fig. 2), which changed a glycine to arginine at amino acid codon 188. This mutant allele, localized in exon IV of the G6Pase gene, exhibited an abnormal migration pattern in SSCP analysis (31). Family studies revealed that both parents were heterozygous, and the patient was homozygous for this mutation (Fig. 3). Specific changes of restriction enzyme sites in the genomic DNA due to these mutations confirmed that these are true mutations, not PCR artifacts (data not shown).

Two additional unrelated GSD 1a patients (from separate families) with homozygous G188R mutations were identified using these screening methods (31) and subsequently shown to have had infections and PMN abnormalities. These included mild chronic neutropenia, decreased oxidative metabolism, impaired chemotaxis, and defective killing of E. coli.

G188R mutation abolishes G6Pase activity. Site-directed mutagenesis of the G6Pase cDNA was performed, and constructs were transiently expressed in COS-7 cells $(3,7)$. The G188R mutation abolished phosphohydrolase activity in transient expression experiments (G6Pase activities were 95, 18, and $15 \mathrm{nmol} \cdot \mathrm{min}^{-1} \cdot \mathrm{mg}^{-1}$ protein in wild-type cDNA, G188R mutant cDNA, and mock transfection, respectively). Thus, transfection of this allele and subsequent enzyme assays show that the G188R mutation results in G6Pase deficiency.

Index case does not have a mutation in the G6P translocase (T1 transporter) gene. All nine exons as well as the first $200 \mathrm{bp}$ of the promoter region of the T1 transporter gene were analyzed by SSCP and heteroduplex analysis. Results were confirmed by sequence analysis of selected regions (12). No mutations in the translocase gene were found.

\section{DISCUSSION}

We report here a group of patients from three unrelated families with hepatic enzymology and mutations in the G6Pase gene characteristic of GSD 1a. Chronic neutropenia, recurrent bacterial infections, and response to cytokine therapy, however, are similar to GSD $1 \mathrm{~b}$ patients at the milder end of the clinical spectrum $(5,26,33,34)$. These patients were able to mount a modest granulocytosis with infections and had variable degrees of PMN dysfunction. The proband, who had significant morbidity due to infections associated with neutro-
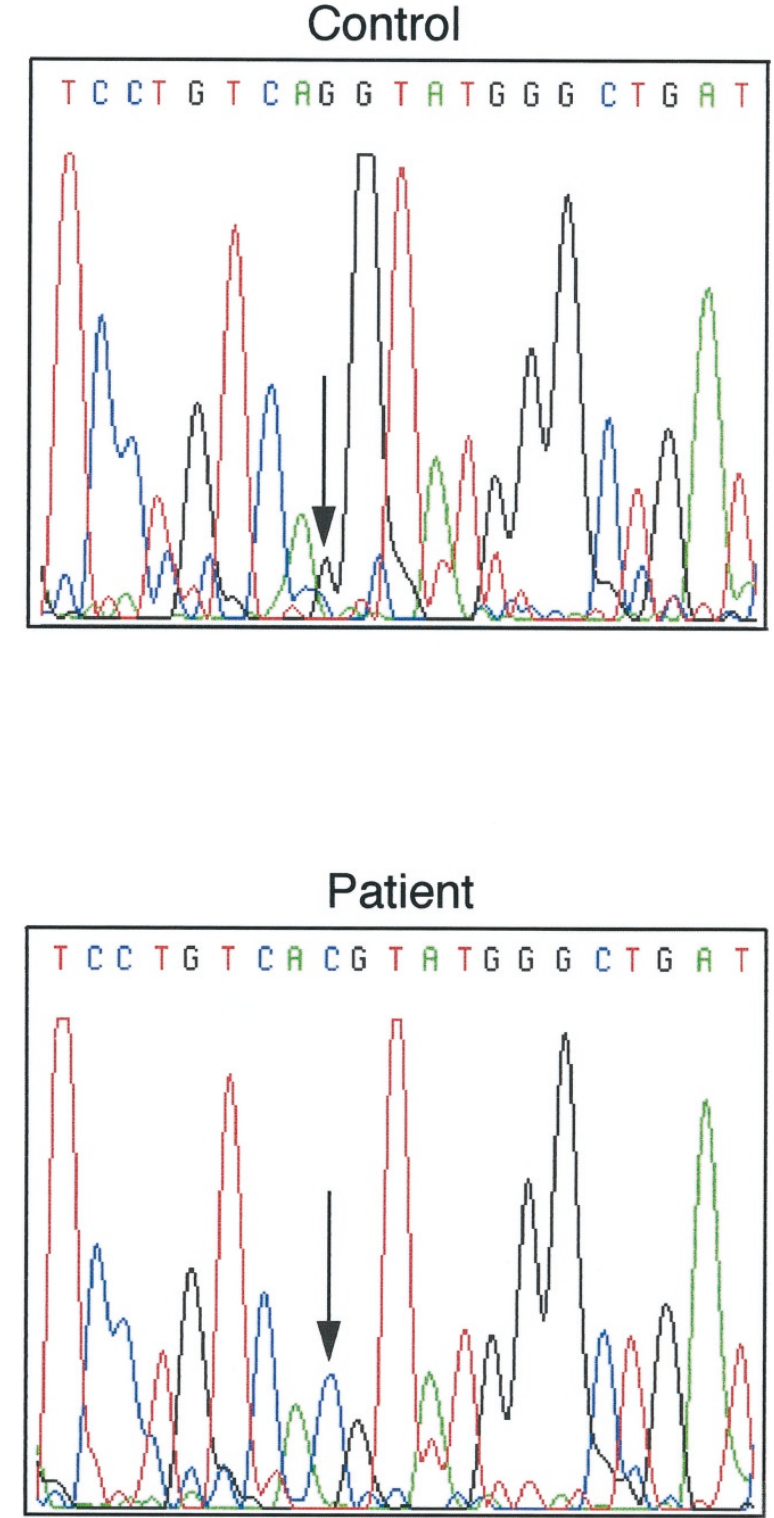

Figure 2. Partial sequence of PCR-amplified G6Pase genomic clones. Fluorescence-based sequencing was performed, and corresponding DNA bases are noted above. The G6Pase gene of the patient contained a $\mathrm{C}$ to $\mathrm{G}$ transversion at nucleotide 641 (arrow) that caused a glycine to arginine substitution (G188R).

penia, responded to G-CSF in a manner similar to GSD $1 \mathrm{~b}$ patients.

Although our findings suggest a role for G6Pase in microsomal membrane transport of G6P (20), it is important to note that the G6Pase gene is not highly expressed in human PMN (13) and that biochemical evidence suggesting catalysisdependent G6P transport is often difficult to interpret. These issues are further complicated by the finding of a G6Pase-like activity in the ER of human PMN and platelets (22). An alternative explanation for our results is that the G188R mutation serves as a marker for a distinct locus involved in PMN function and myelopoiesis. This as yet undefined gene product could be either a membrane or cytosolic component whose function may vary from substrate or product transport to intracellular signaling in leukocytes. 

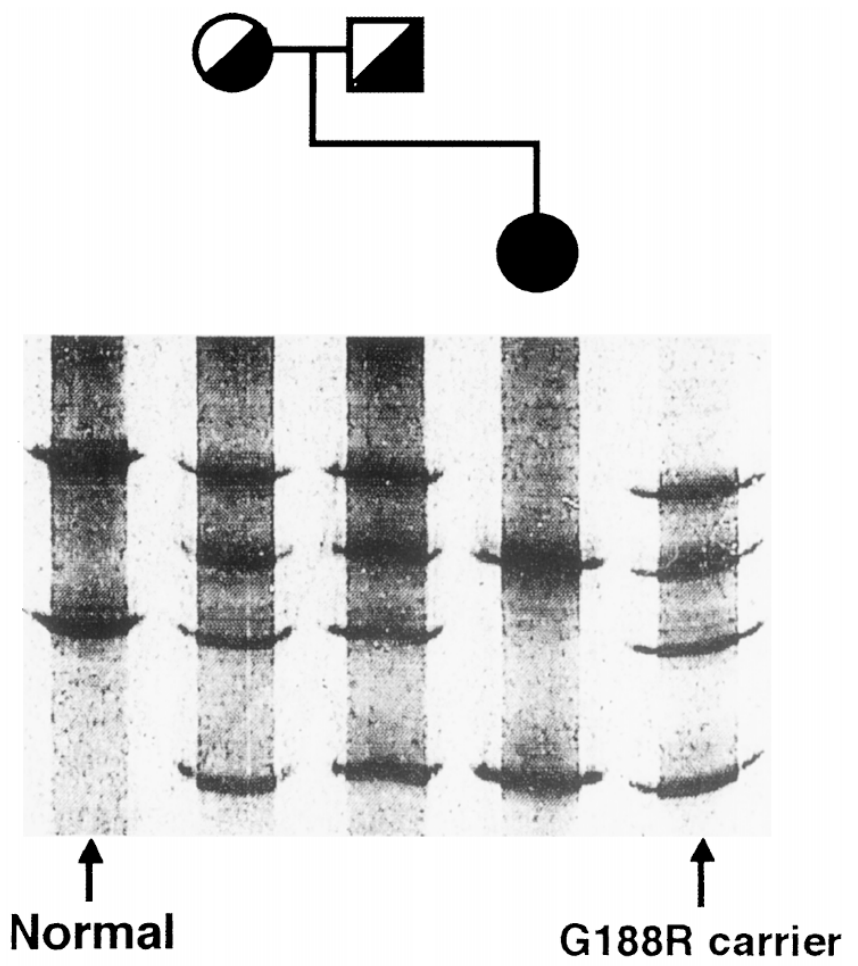

Figure 3. SSCP analysis in exon IV of the G6Pase gene. A normal individual and a known carrier of the G188R mutation were used as controls. The parents (unaffected) are heterozygous for G188R, and the patient is homozygous. Siblings are not shown.

Neutrophil dysfunction in PMN from GSD $1 \mathrm{~b}$ patients receiving G-CSF and GM-CSF has been well described $(26,34)$. As in our index case, two subpopulations of PMN are identified by their capacity to produce superoxide and peroxide, with one population producing normal amounts by both assays (26). This functional heterogeneity is well documented in PMN from G-CSF-responsive GSD 1b patients, but its basis is not known (26). Impaired chemotaxis, the most reproducible defect in GSD $1 \mathrm{~b}$, is not normalized by treatment with G-CSF. Diminished killing of E. coli is also characteristic of GSD 1b PMN (32) and is again noted in our four G6Pase-deficient G188R patients. When considered in the context of chronic neutropenias, these PMN functional findings are not typical of any other heritable or acquired disorder.

Mechanisms responsible for the distinctively abnormal PMN function in GSD 1b are not well understood, however. If the metabolic defect found in GSD 1b hepatocytes is also present in PMN, it would result in a block of G6P transport from the cytosol into the ER. G6P is important in PMN chemotaxis and phagocytosis (35). Degranulation is apparently not affected by microsomal G6P levels (36). Decreased respiratory burst activity is not uniform in GSD $1 \mathrm{~b}$ PMN; some patients have relatively normal values, though methods vary (32-36). These defects are postulated to be caused by variably decreased rates of NADPH biosynthesis in GSD 1b PMN (6). Hexose monophosphate shunt abnormalities have been associated with G6P transport defects (35). Decreased respiratory burst activity seen in PMN from GSD $1 \mathrm{~b}$ patients has also been linked to abnormalities in calcium mobilization (36).
These and other results suggest an intracellular signaling role for the T1 translocase and possibly for certain domain(s) of G6Pase. The G188R mutation is located in the fifth transmembrane domain of G6Pase, the same segment that H176 (the phosphate acceptor site) is located. Given the relatively mild PMN abnormalities in our patients, the results are analogous to a partial rather than complete defect in G6P transport (32). The data are consistent with the notion of G6Pase partially regulating import of G6P through functional interaction with the translocase or other membrane component(s).

Although it is conceivable that we have missed a mutation in an unknown transporter or phosphatase gene in the index case, it is more likely that homozygous G188R mutation of the G6Pase gene accounts for our results. Individuals who are heterozygous for this mutation (37) do not appear to be affected (e.g. parents, Fig. 3). If considering the proband's abnormal neutrophil phenotype and hepatic enzymology to be separate mutational events, the odds that this combination arose due to chance are remote, although we cannot rule out uniparental isodisomy. With an affected sibling and two additional unrelated G188R homozygotes having PMN abnormalities, it is even less likely to be a chance association. Patients with similar mutations in G6Pase should be studied for quantitative and qualitative neutrophil disorders. Future studies will focus on the role of these genes in myeloid development and PMN function.

Acknowledgments. The authors thank Gerald Featherstone, Fernando DiMeo, and Dr. Hui Liu for their technical contributions.

\section{REFERENCES}

1. Hers HG, Berthet J, Berthet L, de Duve C 1951 Le systeme hexose-phosphatasique: localisation intracellulaire des ferments par centrifugation fractionnee. Bull Soc Chim Biol 33:21-41

2. Lei KJ, Shelly LL, Lin B, Sidbury JB, Chen YT, Nordlie RC, Chou JY 1995 Mutations in the glucose-6-phosphatase gene are associated with glycogen storage disease types 1a and 1aSP but not $1 \mathrm{~b}$ and 1c. J Clin Invest 95:234-240

3. Lei KJ, Pan CJ, Liu JL, Shelly LL, Chou JY 1995 Structure-function analysis of human glucose-6-phosphatase, the enzyme deficient in glycogen storage disease type 1a. J Biol Chem 270:11882-11886

4. Arion WJ, Canfield WK, Callaway ES, Burger HJ, Hemmerle H, Schubert G, Herling AW, Oekonomopulos R 1998 Direct evidence for the involvement of two glucose6-phosphate-binding sites in the glucose-6-phosphatase activity of intact liver microsomes. J Biol Chem 273:6223-6227

5. Narisawa K, Otoma H, Igarashi Y, Arai N, Otake M, Tada K, Kuzuya T 1983 Glycogen storage disease type 1b: microsomal glucose-6-phosphatase system in two patients with different clinical findings. Pediatr Res 17:545-549

6. Narisawa K, Igarashi Y, Tada K 1987 Glycogen storage disease type 1b: genetic disorder involving the transport system of intracellular membrane. Enzyme 38:177183

7. Lei KJ, Chen YT, Chen H, Wong LJC, Liu JL, McConkie-Rosell A, Van Hove JLK, Ou HCY, Yeh NJ, Pan LY, Chou JY 1995 Genetic basis of glycogen storage disease type 1a: prevalent mutations at the glucose-6-phosphatase locus. Am J Hum Genet 57:766-771

8. Lei KJ, Pan CJ, Shelly LL, Liu JL, Chou JY 1994 Identification of mutations in the gene for glucose-6-phosphatase, the enzyme deficient in glycogen storage disease type 1a. J Clin Invest 93:1994-1999

9. Kajihara S, Matsuhashi S, Yamamoto K, Kido K, Tsuji K, Tanae A, Fujiyama S, Itoh T, Tanigawa K, Uchida M, Setoguchi Y, Motomura M, Mizuta T, Sakai T 1995 Exon redefinition by a point mutation within exon 5 of the glucose-6-phosphatase gene is the major cause of glycogen storage disease type 1a in Japan. Am J Hum Genet 57:549-555

10. Lei KJ, Shelly LL, Pan CJ, Sidbury JB, Chou JY 1993 Mutations in the glucose-6phosphatase gene that cause glycogen storage disease type 1a. Science 262:580-583

11. Gerin I, Veiga-da-Cunha M, Achouri Y, Collet JF, Van Schaftingen E 1997 Sequence of a putative glucose-6-phosphate translocase, mutated in glycogen storage disease type Ib. FEBS Lett 419:235-238

12. Veiga-da-Cunha M, Gerin I, Chen YT, de Barsy T, de Lonlay P, Dionisi Vici C, Fenske CD, Lee PJ, Leonard JV, Maire I, McConkie-Rosell A, Schweitzer S, Vikkula 
M, Van Schaftingen E 1998 A gene on chromosome 11q23 coding for a putative glucose-6-phosphate translocase is mutated in glycogen-storage disease types Ib and Ic. Am J Hum Genet 63:976-983

13. Lin B, Annabi B, Hiraiwa H, Pan CJ, Chou JY 1998 Cloning and characterization of cDNAs encoding a candidate glycogen storage disease type $1 \mathrm{~b}$ protein in rodents. J Biol Chem 273:31656-31660

14. Hiraiwa H, Pan CJ, Lin B, Moses S, Chou JY 1999 Inactivation of the glucose-6phosphate transporter causes glycogen storage disease type $1 \mathrm{~b}$. J Biol Chem 274:5532-5536

15. Nordlie RC, Sukalski KA, Munoz JM, Baldwin JJ 1983 Type 1c, a novel glycogenosis. J Biol Chem 258:9739-9744

16. Waddell ID, Lindsay JG, Burchell A 1988 The identification of T2, the phosphate/ pyrophosphate transport protein of the hepatic microsomal glucose-6-phosphatase system. FEBS Lett 229:179-182

17. Hawkins RA, Kamath KR, Scott HM, Burchell A 1995 Multiple transport protein defects in a patient with glycogen storage disease type 1: GSD 1b/1c. J Inherit Metab Dis $18: 558-566$

18. Waddell ID, Hume R, Burchell A 1989 A direct method for the diagnosis of human hepatic type $1 \mathrm{~b}$ and type 1c glycogen-storage disease. Clin Sci 76:573-579

19. Burchell A, Allan BB, Hume R 1994 Glucose-6-phosphatase proteins of the endoplasmic reticulum. Mol Membr Biol 11:217-227

20. Lei KJ, Chen H, Pan CJ, Ward JM, Mosinger B, Lee EJ, Westphal H, Mansfield BC, Chou JY 1996 Glucose-6-phosphastase-dependent substrate transport in the glycogen storage disease type-1a mouse. Nat Genet 13:203-209

21. Clottes E, Burchell A 1998 Three thiol groups are important for the activity of the liver microsomal glucose-6-phosphatase system. J Biol Chem 273:19391-19397

22. Nichols BA, Setzer PY, Bainton DF 1984 Glucose-6-phosphatase as a cytochemical marker of endoplasmic reticulum in human leukocytes and platelets. J Histochem Cytochem 32:165-171

23. Kalmar JR, Arnold RR, Warbington ML, Gardner MK 1988 Superior leukocyte separation with a discontinuous one-step Ficoll-Hypaque gradient for the isolation of human neutrophils. J Immunol Methods 110:275-281

24. Szejda P, Parce JW, Seeds MS, Bass DA 1984 Flow cytometric quantitation of oxidative product formation by polymorphonuclear leukocytes during phagocytosis. J Immunol 133:3303-3307

25. Weston BW, Todd RF, Axtell RA, Balazovich KJ, Stewart J, Locey BJ, Mayo-Bond L, Loos P, Hutchinson R, Boxer LA 1991 Severe congenital neutropenia: clinica effects and neutrophil function during treatment with granulocyte-colony stimulating factor. J Lab Clin Med 117:282-290
26. Schroten H, Roesler J, Breidenbach T, Wendel U, Elsner J, Schweitzer S, Zeidler C, Burdach S, Lohmann-Matthes ML, Wahn V, Welte K 1991 Granulocyte and granulocyte-macrophage colony-stimulating factors for treatment of neutropenia in glycogen storage disease type 1b. J Pediatr 119:748-754

27. Cutler CW, Kalmar JR, Arnold RR 1991 Phagocytosis of virulent Porphyromonas gingivalis by human polymorphonuclear leukocytes requires specific immunoglobulin G. Infect Immun 59:2097-2104

28. Cutler CW, Kalmar JR, Arnold RR 1991 Antibody-dependent alternate pathway of complement activation in opsonophagocytosis of Porphyromonas gingivalis. Infect Immun 59:2105-2109

29. Cutler CW, Arnold RR, Schenkein H 1993 Inhibition of C3 and IgG proteolysis enhances phagocytosis of Porphyromonas gingivalis. J Immunol 151:7016-7029

30. Aruffo A 1991 Preparation and analysis of DNA. In: Ausubel FM, Brent R, Kingston R, Moore DD, Seidman JG, Smith JA, Struhl K (eds) Current Protocols in Molecular Biology. Greene Publishing and Wiley-Interscience, New York, pp 16.13.1.-16.13.7

31. Matern D, Lang C, Beck S, Brandis M, Seydewitz HH 1998 Diagnosis of glycogen storage disease type IA: DNA-analysis of leukocytes as an alternative to the enzyme assay in a liver biopsy specimen. Monatsschr Kinderheilkd 146:660-664

32. Koven NL, Clark MM, Cody CS, Stanley CA, Baker L, Douglas SD 1986 Impaired chemotaxis and neutrophil (polymorphonuclear leukocyte) function in glycogenosis type 1 b. Pediatr Res 20:438-442

33. Ambruso DR, McCabe ERB, Anderson D, Beaudet A, Ballas LM, Brandt IK, Brown B, Coleman R, Dunger DB, Falletta JM, Friedman HS, Haymond MW, Keating JP, Kinney TR, Leonard JV, Mahoney DH, Matalon R, Roe TF, Simmons P, Slonim AE 1985 Infectious and bleeding complications in patients with glycogenosis 1b. Am J Dis Child 139:691-697

34. Hurst D, Kilpatrick L, Becker J, Lipani J, Kleman K, Perrine S, Douglas SD 1993 Recombinant human GM-CSF treatment of neutropenia in glycogen storage disease1b. Am J Pediatr Hematol Oncol 15:71-76

35. Bashan N, Hagai Y, Potashnik R, Moses SW 1988 Impaired carbohydrate metabolism of polymorphonuclear leukocytes in glycogen storage disease $1 \mathrm{~b}$. J Clin Invest 81:1317-1322

36. Kilpatrick L, Garty BZ, Lundquist KF, Hunter K, Stanley CA, Baker L, Douglas SD, Korchak HM 1990 Impaired metabolic function and signaling defects in phagocytic cells in glycogen storage disease type 1b. J Clin Invest 86:196-202

37. Chevalier-Porst F, Bozon D, Bonardot AM, Bruni N, Mithieux G, Mathieu M, Maire I 1996 Mutation analysis in 24 French patients with glycogen storage disease type 1a J Med Genet 33:358-360 